Tópico de Interesse Geral

\title{
Ovinocultura do Rio Grande do Sul: descrição do sistema produtivo e dos principais aspectos sanitários e reprodutivos ${ }^{1}$
}

\author{
Ana Paula S. Poeta Silva ${ }^{2 *}$, Diego V. Santos ${ }^{2,3}$, Ivo Kohek Jr ${ }^{3}$, Gustavo Machado ${ }^{2}$, \\ Héber E. Hein ${ }^{2}$, Ana Carla M. Vidor ${ }^{3}$ e Luis Gustavo Corbellini ${ }^{2}$
}

\begin{abstract}
Silva A.P.S.P., Santos D.V., Kohek Jr I., Machado G., Hein H.E., Vidor A.C.M. \& Corbellini L.G. 2013. [Sheep industry in the State of Rio Grande do Sul, Brazil: description of the production system and the main health and reproductive aspects.] Ovinocultura do Rio Grande do Sul: descrição do sistema produtivo e dos principais aspectos sanitários e reprodutivos. Pesquisa Veterinária Brasileira 33(12):1441-1446. Laboratório de Epidemiologia Veterinária, Faculdade de Veterinária, Universidade Federal do Rio Grande do Sul, Av. Bento Gonçalves 9090, Porto Alegre, RS 91540-000, Brazil. E-mail: epilabvet@gmail.com

The sheep industry has always been an important economic and traditional activity in the State of Rio Grande do Sul. In spite of the wool crises occurred in the 1980ies and 1990 ies, the sheep flock remains the largest flock in Brazil. Due to scarcity of recent data on this activity, the present study aims to characterize the sheep industry of Rio Grande do Sul. For this reason, we performed a planned and probabilistic stratified cluster sampling with flocks selected propotionally by seven regions of the State. We analyzed 705 farms through an epidemiological questionnaire, applied by 25 veterinarians from the Department of Animal Health (DDA), of the Secretary of Agriculture, Livestock and Agribusiness of the state of Rio Grande do Sul (SEAPA/RS). According to the results, the sheep industry is essentially extensive and based on production of meat and wool, the main objective of which is subsistence. This indicates that the activity still maintains older standards, with almost no technical improvement regarding sanitary and reproduction aspects. This revels that sheep production in Rio Grande do Sul is still considered as a secondary exploitation of farms, which explains the low investment in this sector.
\end{abstract}

INDEX TERMS: Sheep industry, descriptive epidemiological study, epidemiological questionnaire.

RESUMO.- A ovinocultura sempre foi uma atividade de grande importância econômica e de tradição para o Estado do Rio Grande do Sul (RS), mesmo com as crises da lã ocorridas nas décadas de 80 e 90, o rebanho ovino Gaúcho continua sendo o maior a nível nacional. Com a escassez de dados sobre essa atividade, o presente estudo possui como objetivo caracterizar a ovinocultura do RS. Para isso, foi utilizada uma amostragem planejada, caracterizada pela

\footnotetext{
${ }^{1}$ Recebido em 21 de junho de 2013.

Aceito para publicação em 5 de novembro de 2013.

${ }^{2}$ Laboratório de Epidemiologia Veterinária, Departamento de Medicina Veterinária Preventiva, Faculdade de Medicina Veterinária, Universidade Federal do Rio Grande do Sul (UFRGS), Av. Bento Gonçalves 9090, Porto Alegre, RS 95320-000, Brasil. *Autor para correspondência: paulaserafinipoeta@gmail.com

${ }^{3}$ Departamento de Defesa Animal, Secretária de Agricultura, Pecuária e Abastecimento do Rio Grande do Sul (SEAPA/RS), Av. Getúlio Vargas 1384, Porto Alegre, RS 90150-000.
}

aleatoriedade e estratificação da amostra pelas sete Mesorregiões do Estado. Foram analisadas 705 propriedades rurais através de um questionário epidemiológico, aplicado por 25 veterinários do Departamento de Defesa Animal, da Secretaria da Agricultura, Pecuária e Agronegócio do Estado do Rio Grande do Sul. Conforme os resultados obtidos, a ovinocultura gaúcha é explorada extensivamente e baseada na produção conjunta de carne e lã, cuja principal finalidade é a subsistência. Assim, demonstrando que essa atividade ainda mantém padrões de sua origem, com pouca tecnificação, tanto em aspectos sanitários quanto reprodutivos, revelando, portanto, que a ovinocultura gaúcha ainda é vista como uma produção secundária pelos produtores rurais gaúchos, o que pode ser explicado pelos baixos investimentos neste setor.

TERMOS DE INDEXAÇÃO: Ovinocultura, estudo descritivo epidemiológico, questionário epidemiológico. 


\section{INTRODUÇÃO}

No início do século XX, a produção ovina lanífera recebia grande destaque entre as atividades gaúchas, devido à grande demanda exigida pelo mercado internacional em consequência da Primeira Grande Guerra. Porém, este cenário mudou durante as décadas de 80 e 90, em virtude do rápido crescimento das atividades industriais especializadas e ao alto estoque australiano de lã, ocasionando uma progressiva substituição da lã pelas fibras sintéticas de menor valor têxtil e de fácil adaptação às exigências do mercado internacional (Figueró 1975, Nocchi 2001, Viana 2008). Como consequência, muitos produtores mudaram o foco de suas atividades, ocasionando um declínio marcante no rebanho ovino comercial do Rio Grande do Sul (Bofill 1996, Nocchi 2001). Entretanto, o aumento do poder aquisitivo da população e o aumento do consumo de carne pela população urbana, acarretou na ascensão da comercialização da carne ovina, a qual mostrou uma nova alternativa para ovinocultura (Viana \& Silveira 2008).

Mesmo com esse mercado novamente aquecido, a ovinocultura gaúcha ainda sofre devido à baixa competitividade no mercado internacional, além de apresentar sérias dificuldades para suprir a atual demanda interna sem recorrer a contínuas importações. Esta situação é devido à baixa qualidade da carne produzida, os altos custos da produção e a baixa escala de produção (Calvete \& Villwock 2007). Além disso, possui entraves que impedem o devido desenvolvimento, como a presença de pequenos lotes com falta de homogeneidade corporal, de peso e de idade de terminação e a informalidade da comercialização dos produtos (Osório et al. 2002, Pereira Neto 2004, Silveira 2005, Carvalho 2006).

Atualmente, o Estado continua sendo o principal produtor de ovinos do país, possuindo 3,946 milhões de cabeças e 46 mil propriedades cadastradas, o que representa $23 \%$ do rebanho nacional, localizado principalmente na metade Sul do Estado (IBGE 2010).

Diante de poucas referências atuais sobre a ovinocultura gaúcha, este trabalho tem como objetivo estimar, através de uma amostragem planejada, as principais características produtivas da ovinocultura do Rio Grande do Sul considerando os aspectos de produção e sanitários.

\section{MATERIAL E MÉTODOS}

Foi realizada uma amostragem aleatória estratificada pelas sete mesorregiões do estado do Rio Grande do Sul. Para tanto, foi utilizado o banco de dados do Sistema de Defesa Agropecuária (SDA), no qual estão cadastrados os produtores rurais gaúchos, suas propriedades e animais, sendo mantido, administrado e atualizado pelo Departamento de Defesa Agropecuária (DDA), da Secretaria da Agricultura, Pecuária e Agronegócio do Estado do Rio Grande do Sul (SEAPA/RS). A amostragem foi planejada, inicialmente, para determinar a soroprevalência de Brucella ovis (Epididimite ovina) no RS e os fatores de risco associados a essa doença (Vidor \& Santos 2012). Para o cálculo dessa amostra, tendo como unidade amostral a propriedade rural, assumiu-se uma prevalência esperada de $10 \%$ para a enfermidade pesquisada, nível de confiança de 95\%, precisão de 5\% e uma variação da prevalência entre-propriedades de $42 \%$. Mediante esses parâmetros, seriam necessárias, no mínimo 691 propriedades, sendo que foram amostradas 705 propriedades.
Sendo assim, junto à colheita do soro dos animais, foi aplicado um questionário epidemiológico aos produtores rurais, o qual foi realizado por 25 médicos veterinários do DDA/SEAPA/RS, previamente treinados. 0 trabalho a campo ocorreu durante o mês de novembro de 2011 a fevereiro de 2012. Por meio desse questionário realizou-se um levantamento das informações das propriedades, dos animais e do produtor. Uma cópia desse questionário está disponível mediante solicitação.

Foi criado um banco de dados utilizando o software Epi Info $7.0^{\circledR}$ para que as informações dos questionários fossem compiladas. As análises estatísticas descritivas e espaciais foram realizadas através do programa Microsoft ${ }^{\circledR}$ Office Excel ${ }^{\circledR} 2010$ e ArcGis $^{\circledR}$ 10, respectivamente. Os intervalos de confiança (95\%) foram calculados para os principais parâmetros da caracterização das propriedades (tipo de exploração, aptidão do rebanho e finalidade da criação) levando em consideração a estrutura da amostra estratificada. Foi testada a hipótese de independência entre os indicadores de tecnificação reprodutiva (uso de inseminação artificial e exames clínicos pré-cobertura) e a finalidade de exploração econômica das propriedades (comercial e subsistência) através do teste de qui-quadrado de independência realizado no software Epi Info $7.0^{\circledR}$.

\section{RESULTADOS}

Com a estratificação da amostragem, foi levada em consideração a distribuição das propriedades rurais dentre as sete Mesorregiões do Estado. Logo, as 705 propriedades analisadas foram distribuídas proporcionalmente ao número total de propriedades produtoras de ovinos existentes em cada mesorregião, como mostra o Quadro 1. O questionário epidemiológico dirigido ao produtor rural possibilitou o delineamento de um perfil atual da ovinocultura gaúcha, apresentado nos seguintes tópicos:

\section{Características das propriedades}

As propriedades que desenvolvem a ovinocultura no Estado possuem área total variável entre 0,3 a 6.000 ha (mediana de $51,5 \mathrm{ha}$ ). Pouco mais da metade das propriedades (52\%) possui menos de 50 ha; $35 \%$ possuem entre 50 e 500 ha e $13 \%$ possuem mais de 500 ha de extensão. Sobre a área destinada à ovinocultura nessas propriedades, $31 \%$ usam menos de 5 ha, $51 \%$ entre 5 e 100 ha e $18 \%$ mais de 100 ha. A mesorregião Centro-Ocidental possui as propriedades com maiores extensões para a ovinocultura (mediana de $38 \mathrm{ha}$ ), enquanto que a mesorregião Nordeste as menores (mediana de $8 \mathrm{ha}$ ).

\section{Quadro 1. Número total de propriedades com a sua determinada proporção (entre parênteses) de cada Mesorregião no Rio Grande do Sul, além do número de propriedades amostradas}

\begin{tabular}{lcc}
\hline Mesorregião & $\begin{array}{c}\text { Número total de propriedades } \\
\text { e a proporção (\%) }\end{array}$ & $\begin{array}{c}\text { Número de } \\
\text { propriedades coletadas }\end{array}$ \\
\hline Centro-Ocidental & $5374(11,5 \%)$ & 82 \\
Centro-Oriental & $2359(5,0 \%)$ & 38 \\
Metropolitana & $4114(8,8 \%)$ & 61 \\
Nordeste & $3324(7,1 \%)$ & 49 \\
Noroeste & $8905(19,0 \%)$ & 133 \\
Sudeste & $11154(23,8 \%)$ & 168 \\
Sudoeste & $11644(24,8 \%)$ & 174 \\
TOTAL & $46874(100 \%)$ & 705
\end{tabular}


Quanto à população ovina existente nas propriedades, $31 \%$ possuem menos de 25 animais, $39 \%$ possuem de 25 a 100 animais e $30 \%$ possuem mais de 100 animais. Nesse caso, a mesorregião em destaque é a Centro-Ocidental (mediana de 83 animais por propriedade), como é visto pela Figura 1, onde a maior concentração de ovinos está localizada nas mesorregiões Centro-Ocidental, Sudeste e Sudoeste.

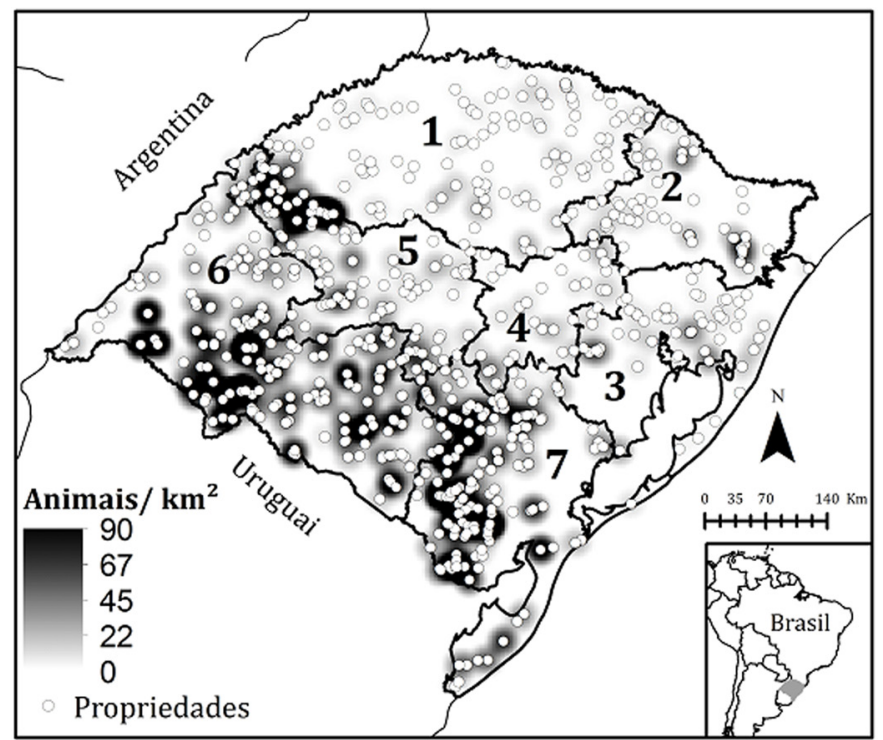

Fig.1. Mapa mostrando a localização geográfica das propriedades amostradas, a concentração dos ovinos (animais $/ \mathrm{km}^{2}$ ) por propriedade e a localização das sete mesorregiões do Estado: (1)Mesorregião Noroeste, (2) Mesorregião Nordeste, (3) Mesorregião Metropolitana, (4) Mesorregião Centro-Oriental, (5) Mesorregião Centro-Ocidental, (6) Mesorregião Sudoeste, (7) Mesorregião Sudeste.
Observou-se ainda que a grande maioria (70\%; IC 95\%: $65-75 \%$ ) das propriedades possui como tipo de exploração o regime extensivo, sendo que as restantes dividem-se em produções do tipo intensivo (1\%; IC 95\%: 0,9-1,1\%) e semi-intensivo (29\%; IC 95\%: 28-30\%). Entretanto, como mostra o Quadro 2, no momento em que se analisam as mesorregiões do Estado, individualmente, verifica-se que a metade Norte do RS possui uma intensificação da produção dos ovinos, enquanto a metade Sul do Estado, ainda mantém seus animais de forma extensiva, livres ao pasto.

Quando questionados sobre a finalidade da produção de ovinos, a maioria dos produtores considerou sua criação como subsistência ou para consumo próprio (74\%; IC 95\%: 69-79\%), e em menor número, (26\%; IC 95\%: 24-28\%) a prática comercial da cria/recria/engorda e a venda de reprodutores. Mas também, analisando cada mesorregião, a região central diverge desses dados, demonstrando sua relevante dedicação à prática comercial dos ovinos (Quadro 2).

A maioria das propriedades tem a presença de bovinos e/ou bubalinos (94\%), cães (96\%) e equinos (80\%), enquanto a metade possui criação de suínos (51\%) e poucas de caprinos (7\%).

\section{Características do rebanho}

Grande parte do rebanho possui como aptidão a produção concomitante de carne e lã (49\%; IC 95\%: 46-51\%), ou somente de carne (43\%; IC 95\%: 39-46\%). Há ainda outros 8\% (IC 95\%: 7-9\%) que destinam os animais apenas para a produção de lã. Nesse estudo não foi amostrada nenhuma propriedade especializada na produção de leite.

O levantamento nas propriedades estudadas mostrou que o rebanho ovino gaúcho é constituído em sua maioria por fêmeas acima de 6 meses (59\%), seguido de fêmeas até

\begin{tabular}{|c|c|c|c|c|}
\hline Mesorregião & $\begin{array}{l}\text { Número de } \\
\text { propriedades } \\
\text { coletadas }\end{array}$ & $\begin{array}{l}\text { Forma de } \\
\text { criação (\%) }\end{array}$ & $\begin{array}{l}\text { Aptidão do } \\
\text { rebanho (\%) }\end{array}$ & $\begin{array}{l}\text { Finalidade da } \\
\text { criação (\%) }\end{array}$ \\
\hline Centro-Ocidental & 82 & $\begin{array}{c}\text { Extensivo: } 90 \\
\text { Semi-intensivo: } 10 \\
\text { Intensivo: } 0\end{array}$ & $\begin{array}{l}\text { Carne e lã: } 71 \\
\text { Carne: } 25 \\
\text { Lã: } 4\end{array}$ & $\begin{array}{c}\text { Subsistência/ } \\
\text { consumo próprio: } 50 \\
\text { Comercial: } 50\end{array}$ \\
\hline Centro-Oriental & 38 & $\begin{array}{c}\text { Extensivo: } 26 \\
\text { Semi-intensivo: } 3 \\
\text { Intensivo: } 71\end{array}$ & $\begin{array}{l}\text { Carne e lã: } 53 \\
\text { Carne: } 29 \\
\text { Lã: } 18\end{array}$ & $\begin{array}{c}\text { Subsistência/ } \\
\text { consumo próprio: } 47 \\
\text { Comercial: } 53\end{array}$ \\
\hline Metropolitana & 61 & $\begin{array}{l}\text { Extensivo: } 46 \\
\text { Semi-intensivo: } 3 \\
\text { Intensivo: } 51\end{array}$ & $\begin{array}{l}\text { Carne e lã: } 62 \\
\text { Carne: } 34 \\
\text { Lã: } 4\end{array}$ & $\begin{array}{l}\text { Subsistência/ } \\
\text { consumo próprio: } 89 \\
\text { Comercial: } 11\end{array}$ \\
\hline Nordeste & 49 & $\begin{array}{c}\text { Extensivo: } 26 \\
\text { Semi-intensivo: } 74 \\
\text { Intensivo: } 0\end{array}$ & $\begin{array}{c}\text { Carne e lã: } 49 \\
\text { Carne: } 47 \\
\text { Lã: } 4\end{array}$ & $\begin{array}{l}\text { Subsistência/ } \\
\text { consumo próprio: } 78 \\
\text { Comercial: } 22\end{array}$ \\
\hline Noroeste & 133 & $\begin{array}{c}\text { Extensivo: } 48 \\
\text { Semi-intensivo: } 52 \\
\text { Intensivo: } 0\end{array}$ & $\begin{array}{l}\text { Carne e lã: } 49 \\
\text { Carne: } 44 \\
\text { Lã: } 7\end{array}$ & $\begin{array}{c}\text { Subsistência/ } \\
\text { consumo próprio: } 82 \\
\text { Comercial: } 18\end{array}$ \\
\hline Sudeste & 168 & $\begin{array}{c}\text { Extensivo: } 87 \\
\text { Semi-intensivo: } 13 \\
\text { Intensivo: } 0\end{array}$ & $\begin{array}{l}\text { Carne e lã: } 35 \\
\text { Carne: } 52 \\
\text { Lã: } 13\end{array}$ & $\begin{array}{l}\text { Subsistência/ } \\
\text { consumo próprio: } 76 \\
\text { Comercial: } 24\end{array}$ \\
\hline Sudoeste & 174 & $\begin{array}{c}\text { Extensivo: } 93 \\
\text { Semi-intensivo: } 7 \\
\text { Intensivo: } 0\end{array}$ & $\begin{array}{l}\text { Carne e lã: } 45 \\
\text { Carne: } 45 \\
\text { Lã: } 10\end{array}$ & $\begin{array}{c}\text { Subsistência/ } \\
\text { consumo próprio: } 76 \\
\text { Comercial: } 24\end{array}$ \\
\hline
\end{tabular}

TOTAL 
6 meses (16\%), machos castrados até 6 meses (13\%), machos castrados acima de 6 meses (8,7\%), machos inteiros acima de 6 meses (2\%), machos inteiros até 6 meses $(1,3 \%)$ e uma minoria por rufiões acima de 6 meses $(0,06 \%)$.

As principais raças dos carneiros presentes no Estado são apresentadas no Quadro 3, com destaque para as raças que compõe quase metade do rebanho: a Corriedale (20\%) e a Ideal $(18,5 \%)$.

\section{Quadro 3. Frequência das principais raças dos carneiros existentes no Rio Grande do Sul baseado em uma amostragem aleatória de 705 propriedades}

\begin{tabular}{lc}
\hline \multicolumn{1}{c}{ Raça } & Frequência \\
\hline Corriedale & $20 \%$ \\
Ideal & $18,5 \%$ \\
Sem Raça Definida & $17 \%$ \\
Texel & $15 \%$ \\
Merino & $11 \%$ \\
Ile de France & $5 \%$ \\
Sulffolk & $4 \%$ \\
Crioula & $2,5 \%$ \\
Hampshire Down & $2,5 \%$ \\
Santa Inês & $1,5 \%$ \\
Outras & $3 \%$ \\
TOTAL & $100 \%$
\end{tabular}

\section{Características reprodutivas e sanitárias}

A grande maioria dos proprietários gaúchos (94\%) utiliza somente o carneiro como manejo reprodutivo, privando-se de qualquer técnica, como a inseminação artificial, sincronização e detecção de cios. Além disso, uma minoria realiza algum tipo de exame clínico antes da época de cobertura (menos de 10\%), como a palpação testicular (9\%), a avaliação do perímetro escrotal (7\%) e a avaliação morfológica do sêmen (6\%). A hipótese nula de independência dessas duas variáveis foi rejeitada, aceitando que existe associação entre uso de inseminação artificial $\left(X^{2}=33,85\right.$; $\mathrm{p}<0,001)$ e realização de exames clínicos pré-cobertura $\left(X^{2}=38,72 ; \mathrm{p}<0,001\right)$ com a prática comercial das propriedades. Sendo assim, existe maior probabilidade de uma propriedade caracterizada para fins comerciais realizar inseminação artificial (OR: 5,61 IC95\%: 2,96-10,65) e exames clínicos pré-cobertura nos carneiros (OR: 4,67 IC95\%: $2,79-7,79$ ). Sobre as vacinas utilizadas contra certas doenças infecciosas (raiva, clostridiose, linfadenite caseosa, ectima contagioso, ceratoconjuntivite e pododermatite); $40 \%$ dos proprietários vacinam pelo menos para uma dessas doenças, os outros $60 \%$ não realizam vacinação. Sobre a utilização de vermífugos, a maioria dos proprietários (76\%) realiza vermifugação mais de três vezes por ano.

Além disso, foi questionando aos proprietários se estes possuíam algum tipo de preocupação sanitária com determinadas enfermidades e parasitoses. Verminoses (94\%), piolheiras (51\%), sarnas (42\%), pododermatite ovina (29\%), hidatidose (12\%) e brucelose $(12 \%)$ foram assinaladas como as mais importantes pelos proprietários.

\section{DISCUSSÃO}

De acordo com as informações referentes à área das propriedades, foi demonstrada uma alta variabilidade do per- fil dos ovinocultores na atualidade no RS. A alta amplitude pode ser explicada pela disparidade do tipo e da forma de produção entre a metade Norte e Sul do Estado. As maiores propriedades, além da maior concentração de ovinos e a maior produção, são encontradas nas mesorregiões Sudoeste e Sudeste (Fig.1), resultados que concordam com o levantamento de 2009 realizado pela SEAPA/RS, no qual foi constatado que $53 \%$, e $23 \%$ de todo o rebanho ovino gaúcho localizava-se nessas mesorregiões, respectivamente (Santos et al. 2011). Todavia, a mesorregião Centro-Ocidental mostrou um grande crescimento tanto no número de ovinos, quanto em propriedades.

Sobre a distribuição do número de animais nas categorias especificas, esse mesmo estudo (Santos et al. 2011) mostrou que o rebanho ovino vem seguindo uma linha de crescimento desde 2007, fato que pode ser explicado pelo alto número de fêmeas, especificamente, acima de seis meses de idade, futuras matrizes, que estão sendo mantidas a campo ao invés de serem abatidas. Isso já pode ser um reflexo do programa gaúcho "Mais ovinos no campo" implantado pelo governo do Rio Grande do Sul em 2010, o qual visa estimular os produtores rurais de ovinos a reterem as matrizes no campo, com a finalidade de aumentar o plantel de ovinos no Estado (SEAPA/RS 2010).

A principal forma de exploração do RS continua sendo extensiva, entretanto, esse cenário muda quando se observa as singularidades das mesorregiões, demonstrado pelo Quadro 2, ou seja, existe uma alta frequência de propriedades que possuem algum tipo de intensificação da produção na metade norte do Estado.

Outro ponto importante é a presença de outras criações nessas propriedades, como, por exemplo, a bovinocultura, sugerindo, na maior parte das vezes, que a ovinocultura é uma atividade secundária. Este fato pode ser explicado, também, pelo baixo índice de uso da terra para essa atividade, a baixa quantidade de animais por propriedade, além de que somente um quarto dos produtores possui criação de ovinos com finalidade comercial.

A produtividade da ovinocultura é associada, principalmente, à taxa de prenhez das fêmeas, a sua prolificidade e a taxa de desmame do rebanho (Horn 2013). Todavia, a não utilização de técnicas reprodutivas, a falta de manejo reprodutivo tanto com as fêmeas, quanto com os machos; também contribuem com os baixos índices produtivos do RS. Como mostrou o teste qui-quadrado de independência, a tecnificação da ovinocultura somente é encontrada em propriedades que possuem a finalidade comercial, ou seja, em uma pequena parcela do Estado (26\%).

Pelo menos $90 \%$ dos produtores destinam seus animais para a produção de carne, o que confirma os acontecimentos passados sobre o desenvolvimento da ovinocultura gaúcha, em que os produtores, perante a crise da lã no século XX, dedicaram-se a comercialização da carne como alternativa. 0 Quadro 2 apresenta dados que sugerem esse fato, uma vez que todas as sete mesorregiões são grandes produtoras de carne. Entretanto, a produção de lã não foi esquecida, e ainda contribui com a renda desses produtores.

Esse aspecto é demonstrado, também, pelas caracterís- 
ticas das duas principais raças de carneiros presentes no RS: Corriedale e Ideal. São raças originárias da Nova Zelândia e Austrália, respectivamente, de duplo propósito (produtoras tanto de lã, quanto carne), bem adaptadas à rusticidade do campo e aos sistemas extensivos.

As verminoses juntamente com as ectoparasitoses são responsáveis pelos maiores prejuízos na ovinocultura, provocando acentuada redução de peso, desvalorização da lã e da carne e a alta taxa de mortalidade (Pinheiro 1979). Um exemplo de verminoses é a infestação por Haemonchus contortus, que foi a enfermidade mais diagnosticada na região central do RS durante os anos de 1990 a 2007, segundo um estudo de Rissi et al 2010. Além disso, as verminoses são assinaladas por serem de difícil controle, sejam pelas poucas informações sobre o correto período dos tratamentos ou a escolha das drogas antiparasitárias (Climeni 2008). A frequente utilização de vermífugos pela grande maioria, pelos menos $74 \%$ dos produtores utilizam vermífugos mais de três vezes ao ano no RS, é atribuída às incertezas do tratamento e às perdas ocasionadas.

A hidatidose é uma parasitose causada pelo Echinococcus granulosus (tênia de cães), que acomete diversos animais domésticos. Caracteriza-se pela formação de cistos hidáticos em vários órgãos de ovinos, caprinos e humanos (Fortes 1997). No ano de 2009, a frequência de hidatidose em ovinos foi estimada em $26,3 \%$, através de lesões características em frigoríficos na microrregião de Pelotas/RS (Duval et al. 2010). Em vista disso, destaca-se negativamente que apenas uma minoria dos produtores possui algum tipo de atenção com essa enfermidade (12\%). Esse problema pode ser ainda mais agravado pelo uso dos ovinos para consumo próprio (sem a devida inspeção da carne), visto que se trata de uma zoonose.

Sobre as duas doenças infecciosas apontadas pelos proprietários, a pododermatite ovina ou "foot rot" detém um pouco mais de atenção dos proprietários, uma vez que surtos de foot rot em ovinos lanados são relativamente frequentes no RS (Ribeiro 2007). 0 agente principal da doença é a bactéria Dichelobacter nodosus, no entanto, para a ocorrência da infecção deve existir uma ação sinérgica com a Fusobacterium necrophorum, a qual está presente no solo e fezes (Aguiar et al. 2011). É uma infecção que atinge o espaço interdigital e o tecido córneo dos dígitos, tendo como principal sinal a manqueira, isso faz com que os animais apresentam dificuldade na alimentação e reprodução (Ribeiro 2007).

Já a preocupação da minoria a respeito da brucelose ovina é preocupante, pois trata-se de uma importante enfermidade reprodutiva da ovinocultura. Causada pela bactéria Brucella ovis, sua infecção é associada à epididimite nos carneiros e aos abortos esporádicos nas ovelhas. Magalhães Neto \& Gil-Turnes et al. (1996) examinaram soros de 1638 ovinos machos e encontraram anticorpos anti-Brucella ovis em 13,4\% dos machos do RS. Já no ano de 2012, a prevalência estimada foi de 2,8\% (Vidor \& Santos 2012), mesmo com essa queda, dados ainda demonstram a sua presença no Estado.

A utilização de vacinas contra algumas principais doenças infecciosas da ovinocultura é realizada por menos da metade dos produtores gaúchos (40\%), justificando o pouco interesse e preocupação dos mesmos com relação à prevenção e controle de enfermidades. Isso pode contribuir também o fato que alguns produtores ainda não veem a ovinocultura como uma fonte de renda, portanto não despendem investimentos na sanidade dos animais, tendo-os apenas para a sua subsistência.

\section{CONCLUSÕES}

Com o presente estudo, foi possível realizar um retrato atual da ovinocultura do RS. Conclui-se que essa atividade ainda mantém os padrões do início da sua formação, sendo fundamentalmente explorada de forma extensiva e produzida concomitantemente com outras atividades, principalmente com a espécie bovina. A base da ovinocultura ainda está localizada nas mesorregiões Sudeste e Sudoeste; são nessas que se encontram as maiores áreas destinadas a essa criação, além do maior número de ovinos.

A falta de técnicas reprodutivas e medidas sanitárias que visam aumentar a produtividade e qualidade do rebanho restringem os produtores à criação de poucos ovinos e à dificuldade da comercialização de seus produtos.

Entretanto, mesmo com diversos obstáculos, o alto percentual de cordeiras reprodutoras sinaliza que a população ovina gaúcha mantém o seu padrão de crescimento. Fato que ainda define o Estado no topo da ovinocultura nacional. É essencial que existam esforços coordenados da iniciativa privada em consonância com o governo estadual e federal para alavancar a ovinocultura no RS, tornando essa atividade novamente rentável e consolidada, gerando divisas para o Estado e uma fonte de renda concreta aos produtores.

Agradecimentos.- A todos os 25 médicos veterinários e seus auxiliares, servidores do DDA/SEAPA que aplicaram os questionários a campo. Aos médicos veterinários Roberto Azambuja e Antônio Augusto Rosa Medeiros pela colaboração e discussão dos resultados. Ao FUNDESA e o Acordo de Cooperação Técnica pelo financiamento desse trabalho.

\section{REFERÊNCIAS}

Aguiar G.M.N., Simões S.V.D., Silva T.R., Assis A.C.O., Medeiros J.M.A., Garino Jr F. \& Riet-Correa F. 2011. Foot rot and other foot diseases of goat and sheep in the semiarid region of northeastern Brazil. Pesq. Vet. Bras. 31(10):879-884.

Bofill F.J. 1996. A Reestruturação da Ovinocultura Gaúcha. Livraria e Editora Agropecuária, Guaíba, RS. 137p.

Calvete R. \& Villwock L.H. 2007. Perfil da ovinocultura de lã e carne do Rio Grande do Sul e seus desafios para o futuro. Anais 45 Congresso da Sociedade Brasileira de Economia, Administração e Sociologia Rural, Londrina, PR.

Carvalho R.B. 2006. Potencialidades dos mercados para os produtos derivados de caprinos e ovinos. Capritec, Campinas. Disponível em <http// www.capritec.com.br/art040521.htm> Acesso em 20 dez. 2012.

Climeni B.S.O. 2008. Hemoncose ovina. Revta Cient. Eletr. Med. Vet., São Paulo, 6(11):1-7.

Duval L.H., Tejada T.S., Lansini V., Vidor A.C. \& Duval E.H. 2010. Prevalência de hidatidose em ovinos abatidos sob inspeção Estadual na região de Pelotas/RS. Anais 19o Congresso de Iniciação Científica, Pelotas, RS.

Figueiró C.M.W. 1975. Ovinocultura no Rio Grande do Sul. Secretaria da Agricultura, Porto Alegre. 45p.

Fortes E. 1997. Parasitologia Veterinária. Sulina, Porto Alegre. 606p.

Horn J.A. 2013. Desempenho reprodutivo de ovelhas Texel suplementadas no pré-encarneiramento. Dissertação de Mestrado em Fisiopatologia da Reprodução Animal, Faculdade de Medicina Veterinária, Universidade Federal do Rio Grande do Sul, Porto Alegre. 45p. 
IBGE 2010. Censo Agropecuário. Instituto Brasileiro de Geografia e Estatística, Brasília, DF. Disponível em <http://www.ibge.gov.br/home/ estatistica/economia/ppm/2010/tabelas_pdf/tab17.pdf> Acesso em 15 dez. 2012.

Magalhães Neto A. \& Gil-Turnes C. 1996. Brucelose ovina no Rio Grande do Sul. Pesq. Vet. Bras. 16(2/3):75-79.

Nocchi E.D. 2001. Os efeitos da crise da lã no mercado internacional e os impactos socioeconômicos no município de Santana do Livramento/ RS, Brasil. Dissertação de Mestrado em Integração e Cooperação Internacional, Centro de Estudos em Relaciones Internacionales de Rosário, Universidad Nacional de Rosario, Rosario, Argentina. 71p.

Osório J.C., Osório M.T.M. \& Oliveira N.M. 2002. Qualidade, Morfologia e Avaliação de Carcaças. Universidade Federal de Pelotas, Pelotas, RS. 196p.

Pereira Neto 0. 2004. Práticas em Ovinocultura: ferramentas para o sucesso. SENAR-RS, Porto Alegre. 136p.

Pinheiro A.C. 1979. Aspectos da verminose dos ovinos. Anais 1 1 a Jornada de Produção Ovina no Rio Grande do Sul. Bagé, RS, p.140-148.

Ribeiro L.A.O. 2007. Foot rot dos ovinos, p.295-305. In: Riet-Correa F., Schild A.L., Lemos R.A.A. \& Borges J.R.J. (Eds), Doenças de Ruminantes e Equinos. Vol.1. 3a ed. Varela, São Paulo.
Rissi D.R., Pierezan F., Oliveira Filho J.C., Fighera R.A., Irigoyen L.F., Kommers G.D. \& Barros C.S.L. 2010. Doenças de ovinos da região Central do Rio Grande do Sul: 361 casos. Pesq. Vet. Bras. 30:21-28

Santos D.V., Azambuja R.M. \& Vidor A.C.M. 2011. Dados populacionais do rebanho ovino gaúcho. Hora Vet., Porto Alegre, 31:41-44.

SEAPA/RS 2010. Programa mais Ovinos no Campo. Secretaria de Agricultura, Pecuária e Agronegócio do Rio Grande do Sul, Porto Alegre. Disponível em <http://www.agricultura.rs.gov.br/conteudo/1033/?Mais_ Ovinos_no_Campo> Acesso em 25 mar. 2013.

Silveira H.S. 2005. Coordenação na cadeia produtiva de ovinocultura: o caso do conselho regulador Herval Premium. Dissertação de Mestrado em Agronegócios, Centro de Estudos e Pesquisas em Agronegócios, Universidade Federal do Rio Grande do Sul, Porto Alegre, RS. 104p.

Viana J.G.A. \& Silveira V.C.P. 2008. Análise econômica da ovinocultura na metade sul do Rio Grande do Sul. Anais 46을 Congresso da Sociedade Brasileira de Economia, Administração e Sociologia Rural, Rio Branco, AC.

Vidor A.C.M. \& Santos V.D. 2012. Estudo epidemiológico para determinar a prevalência da brucelose ovina em machos no estado do Rio Grande do Sul. Anais $1^{\circ}$ Encontro Nacional de Epidemiologia Veterinária, São Paulo, SP, p.82. (Resumo) 